\title{
Feasibility of intercostal high intensity focused ultrasound ablation of clinically relevant volumes under the application of beam shaping
}

\author{
Martijn de Greef ${ }^{1 *}$, Gerald Schubert ${ }^{2}$, Joost Wijlemans ${ }^{1}$, Julius Koskela ${ }^{2}$, Lambertus W. Bartels ${ }^{1}$, Chrit Moonen', \\ Mario Ries ${ }^{1}$
}

From Current and Future Applications of Focused Ultrasound 2014. 4th International Symposium

Washington, D.C, USA. 12-16 October 2014

\section{Background/introduction}

Obstruction by the thoracic cage of the high intensity focused ultrasound (HIFU) beam is one of the major challenges in the ablation of abdominal lesions. Several beam shaping methods have been proposed to reduce exposure of the ribs to acoustic energy and to recover focal point intensity. The feasibility of HIFU ablation of a clinically relevant volume applying beam shaping remains however unaddressed. In this study, feasibility was evaluated based on exposure of both the ribs as well as the near-field to acoustic energy. In addition, the volumetric ablation rate was estimated to evaluate whether clinically relevant ablation speeds can be achieved.

\section{Methods}

To establish a safety limit for the exposure of the ribs to acoustic energy, rib heating was studied in an in vivo porcine model using MR thermometry (Achieva, Philips Healthcare, Best, the Netherlands). The animals $(\mathrm{n}=2)$ were installed on the Sonalleve V2 HIFU platform (Philips Healthcare, Vantaa, Finland) and sonications $(\mathrm{n}=3)$ were performed for transducer positions where rib obstruction occurred. Ray tracer simulations were used to estimate the corresponding exposure to acoustic energy. Four different sonication geometries were defined (sonication at $30 \mathrm{~mm}$ and $50 \mathrm{~mm}$ behind rib cage at both $15 \mathrm{~mm}$ and $20 \mathrm{~mm}$ rib spacing) for which single point sonication and volumetric sonications (circular trajectory with $2 \mathrm{~mm}$ and $4 \mathrm{~mm}$ diameter) were simulated. Based on the time required to achieve $65{ }^{\circ} \mathrm{C}$ in a defined ROI according to simulation, acoustic energy density at the ribs and the fat - muscle interface was estimated based on ray tracer and ASPW simulations of the acoustic intensity, respectively. Beam shaping was based on rib ray collision detection and total acoustic power was kept constant. The volumetric ablation rate was estimated based on the ablated volume according to the defined ROI and the inter-sonication waiting time based on a cycle-average energy deposition rate of $100 \mathrm{~kJ} / \mathrm{h}$.

\section{Results and conclusions}

Based on MR thermometry, rib temperature increases of $20-34{ }^{\circ} \mathrm{C}$ were observed at simulated acoustic energy densities of $5.4-6.6 \mathrm{~J} / \mathrm{mm} 2$ (minimum of the $10 \%$ surface with the highest exposure). With increasing volume ablated in a single sonication, the near-field energy density at the fat - muscle interface increased with peak levels above $5 \mathrm{~J} / \mathrm{mm} 2$ in case of sonication with a $4 \mathrm{~mm}$ diameter circular trajectory (safety limit $2.5 \mathrm{~J} / \mathrm{mm} 2$ ). The corresponding rib acoustic energy density in the $1 \mathrm{~cm} 2$ of rib surface with the highest exposure was $<1 \mathrm{~J} / \mathrm{mm} 2$ for $30 \mathrm{~mm}$ and $<2 \mathrm{~J} / \mathrm{mm} 2$ for $50 \mathrm{~mm}$ sonication depth. For the sonication scenarios for which the near-field energy density was within the specified limits, volumetric ablation rates of $\leq 1 \mathrm{ml} / \mathrm{h}$ were estimated. In conclusion, beam shaping by means of the collision detection method is an effective means to protect the ribs against excessive heating. However, by conserving the total acoustic power emitted, this mitigated risk is replaced by the risk of excessive near-field heating. As a consequence, for the particular hardware studied, the volume that can be ablated in a single sonication is required to be limited and this limits the volumetric ablation rate.

${ }^{1}$ University Medical Center Utrecht, Utrecht, Netherlands

Full list of author information is available at the end of the article 


\section{Acknowledgements (Funding)}

This work was financially supported by the Center for Translational Molecular Medicine (CTMM), project VOLTA (grant 05T-201).

\section{Authors' details}

'University Medical Center Utrecht, Utrecht, Netherlands. ${ }^{2}$ Philips Healthcare, Vantaa, Finland.

Published: 30 June 2015

doi:10.1186/2050-5736-3-S1-086

Cite this article as: de Greef et al: Feasibility of intercostal high intensity focused ultrasound ablation of clinically relevant volumes under the application of beam shaping. Journal of Therapeutic Ultrasound 20153 (Suppl 1):086.

Submit your next manuscript to BioMed Central and take full advantage of:

- Convenient online submission

- Thorough peer review

- No space constraints or color figure charges

- Immediate publication on acceptance

- Inclusion in PubMed, CAS, Scopus and Google Scholar

- Research which is freely available for redistribution

Submit your manuscript at www.biomedcentral.com/submit 